\title{
A RESPONSABILIDADE DA AUTARQUIA PREVIDENCIÁRIA (INSS) PELOS DESCONTOS DE CRÉDITOS BANCÁRIOS ORIUNDOS DE EMPRÉSTIMOS CONSIGNADOS EM BENEFÍCIOS PREVIDENCIÁRIOS
}

\author{
Igor Henrique dos Santos Luz ${ }^{1}$
}

\begin{abstract}
RESUMO: Este estudo trata do empréstimo consignado em folha de pagamento instituído pela Lei $\mathrm{n}^{\circ}$. 10.820/03, após a alteração que lhe deu a Lei $\mathrm{n}^{\circ}$. 10.953/04, que ocasiona descontos nos benefícios previdenciários de aposentados e pensionistas do RGPS. Analisa a relação de consumo bancária, a responsabilidade civil objetiva da instituição financeira e da autarquia previdenciária, bem como os fundamentos que a amparam.
\end{abstract}

PALAVRAS-CHAVE: benefício previdenciário; empréstimo consignado em folha; descontos indevidos;

\section{Aspectos Introdutórios e Conceituais do Empréstimo Consignado em Folha de Pagamento}

O contrato de empréstimo bancário, verdadeiro contrato de mútuo, segundo a definição de FÁBIO ULHOA COELHO (2002, p. 122), é “[...] o contrato pelo qual o banco empresta certa quantia de dinheiro ao cliente, que se obriga a restitui-la, com os acréscimos remuneratórios, no prazo contratado. O matiz dessa figura contratual, evidentemente, é o mútuo civil, empréstimo de coisa fungível (CC-02, art. 586; CC-16, art.1.256). Ganha, no entanto, o contrato alguns contornos próprios quando o mutuante é instituição financeira. A particularidade do mútulo bancário, relativamente ao civil, diz respeito aos juros" (grifos nossos).

Com efeito, a diferença entre os contratos de mútuo bancário e mútuo civil encontra amparo na taxa de juros aplicável a cada uma destas espécies, pois “A diferença entre o mútuo civil e o bancário diz respeito aos juros. No civil, as partes não podem contratá-los superiores à taxa SELIC para negociação dos títulos da dívida pública federal,

\footnotetext{
${ }^{1}$ Especialização em Pós-Graduação em Direito Previdenciário pela Universidade Estadual de Londrina, Brasil(2012) Analista Judiciário - Área Judiciária do Tribunal Regional Federal da 4a Região , Brasil. E-mail: igorhenriqueluz@yahoo.com.br

- Artigo recebido em 23/10/2013 e aprovado para publicação em 17/06/2014
} 
ao passo que no mútuo bancário não existem limites legais" (ULHOA COELHO, 2002, p. 124).

Analisando-se o contrato bancário de empréstimo consignado em folha de pagamento como modalidade de contrato de mútuo bancário, tem-se que " $E$ um contrato real, porque somente existe com a entrega da coisa; é unilateral, porque apenas o mutuário assume obrigações, uma vez que o mutuante já prestou, e suas demais obrigações são restritas a não cobrar antes do vencimento (que é obrigação comum a todos os credores e pode ser excepcionada quando for caso de vencimento antecipado) e a eventualmente fiscalizar a aplicação do financiamento quando isso constar do contrato celebrado para fim específico, como acontece no sistema financeiro da habitação, nos créditos para investimentos de interesse social, no crédito agrícola ou industrial, etc. É oneroso, pois supõe o pagamento de juros (ou interesses)" (AGUIAR JÚNIOR, 2003, p.21).

Colhe-se, daí, que o contrato bancário de empréstimo consignado é o negócio jurídico por meio do qual o mutuante cede a propriedade de valor em dinheiro ou que nele se possa expressar (crédito) ao mutuário, com ou sem garantia, para que este lhe a restitua em determinado prazo previamente avençado, com o facilitador de que referida quantia, objeto do negócio jurídico descrito, será debitada, automaticamente, pelo empregador - sob pena de responsabilidade por falha ou culpa, ou, pela entidade autárquica da Previdência Social, da folha de pagamento do empregado, aposentado ou pensionista mutuário, até o limite de 30\% (trinta por cento) ou 40\% (quarenta por cento) conforme o caso, e, repassada ao mutuante até o quinto dia útil após o recebimento ou creditamento da remuneração devida ao mutuário.

O benefício advindo desta modalidade contratual, regida, em especial, pela Lei $n^{\circ} .10 .820 / 03$ e pelo Decreto $n^{\circ} .4 .840 / 03$, encontra-se na segurança e rapidez no recebimento do crédito objeto do mútuo bancário, retirando do mutuário qualquer escolha relativa ao adimplemento, ou não, das obrigações assumidas.

\section{O Contrato de Mútuo Bancário e a Aplicação do Código de Defesa do Consumidor como Mecanismo de Tutela}

Faz-se mister demonstrar não mais existir discussão sobre a aplicação do Código de Defesa do Consumidor às relações jurídicas mantidas com as instituições financeiras, por caracterizarem-se referidas instituições como fornecedoras de serviços, nos 
moldes dispostos pelo artigo $3^{\circ}$, da Lei $\mathrm{n}^{\circ}$. 8.078/1990, que define: "Fornecedor é toda pessoa física ou jurídica, pública ou privada, nacional ou estrangeira, bem como os entes despersonalizados, que desenvolvem atividade de produção, montagem, criação, construção, transformação, importação, exportação, distribuição ou comercialização de produtos ou prestação de serviços", e seu $\S 2^{\circ}$, donde se extrai que "Serviço é qualquer atividade fornecida no mercado de consumo, mediante remuneração, inclusive as de natureza bancária, financeira, de crédito e securitária, salvo as decorrentes das relações de caráter trabalhista" (grifos nossos).

Corroborando este entendimento, o Colendo Superior Tribunal de Justiça editou o enunciado sumular $n^{\circ}$. 297, cujo conteúdo preclara que "O Código de Defesa do Consumidor é aplicável às instituições financeiras", pacificando a questão.

A jurisprudência de nossos Tribunais, igualmente, não se dissocia desta orientação, estendendo os ideais e mecanismos de tutela previstos pelo Código de Defesa do Consumidor aos negócios jurídicos de caráter bancário, como se colhe dos julgados nas AC 200771000191163 do Tribunal Regional da 4 ${ }^{\text {a }}$ Região e AC 200261070059789 do Tribunal Regional Federal da $3^{\text {a }}$ Região.

Neste sentido, ainda, leciona SÉRGIO CAVALIERI FILHO (2007, p. 469), ao asseverar que "O Código de Defesa do Consumidor, justamente para afastar esse tipo de discussão, expressamente incluiu as atividades bancárias e securitárias no conceito legal de serviços, não havendo como afastar a sua incidência desses segmentos do mercado de consumo, a menos que se negue vigência à lei. Não há dúvida de que bancos e seguradoras têm as suas legislações próprias disciplinando o seu funcionamento; mas, no que for pertinente às relações de consumo, ficam também sujeitos à disciplina do Código de Defesa do Consumidor" (grifos nossos).

Afere-se, com isso, que todo empregado, aposentado ou pensionista que pactue a contratação de empréstimo consignado (mútuo bancário) com desconto em folha de pagamento goza, no âmbito da relação jurídica estabelecida com a instituição financeira, da proteção que lhe é conferida pela Lei $\mathrm{n}^{\circ}$. 8.078/1990, em especial, das garantias por ela elencadas em seus artigos $6^{\circ}$ e $7^{\circ}$. 
Consoante dispõe o artigo $6^{\circ}$, da Lei $n^{\circ}$. 10.820/03, após a redação que lhe foi dada pela Lei $\mathrm{n}^{\circ} .10 .953 / 04$, os titulares dos benefícios de aposentadoria e pensão (não incluídos os demais benefícios previdenciários ou assistenciais) do Regime Geral de Previdência Social poderão autorizar o Instituto Nacional do Seguro Social a proceder aos descontos referidos no artigo $1^{\circ}$ da Lei $\mathrm{n}^{\circ}$. 10.820/03 e/ou autorizar, de forma irrevogável e irretratável, que a instituição financeira na qual recebam seus benefícios retenha, para fins de amortização do saldo devido pelo mutuário, valores referentes ao pagamento mensal de empréstimos, financiamentos e operações de arrendamento mercantil por ela concedidos, desde que haja previsão contratual expressa a respeito e observância das condições estabelecidas pela autarquia previdenciária em regulamento (ato próprio) por ela editado.

Ou seja, a autarquia previdenciária atua na condição de órgão gestor intermediário no bojo da relação de consumo "sub analisis", haja vista sua incumbência regimental de "promover o reconhecimento de direito ao recebimento de benefícios administrados pela Previdência Social, assegurando agilidade, comodidade aos seus usuários e ampliação do controle social" (artigo $1^{\circ}$, do Decreto ${ }^{\circ}$. 7.556/11), bem como seu dever de gerir e manter os benefícios concedidos no âmbito do Regime Geral de Previdência Social através de sua Diretoria de Benefícios (artigo 15, do Decreto ${ }^{\circ}$. 7.556/11).

Para levar a efeito esta atuação, a autarquia previdenciária, como ente da Administração Indireta que é, e, portanto, vinculado ao postulado da estrita legalidade, estatui normas procedimentais aptas ao desenvolvimento da finalidade prevista em lei, através da Instrução Normativa INSS/PRES 28/2008.

Referida Instrução Normativa, como a própria denominação deixa antever, é ato normativo emanado da Administração Pública, vinculando aos seus preceitos, tão somente, os servidores e demais agentes públicos que dela se utilizam para a consecução das operações de transferência de crédito decorrentes do empréstimo consignado regulado pela Lei $n^{\circ}$. 10.820/93 e pelo Decreto $n^{\circ} .4 .840 / 03$.

Dentre as diversas normas procedimentais estatuídas no ato normativo administrativo (INSS/PRES 28/2008), extraem-se algumas cujo conteúdo, além de demonstrar a incidência do Código de Defesa do Consumidor sobre as operações por ela regulamentadas, denota a existência de garantias básicas ao consumidor, o qual se vê, em uma mesma relação jurídica, sob duas perspectivas distintas, quais sejam, a de consumidor e a de 
administrado, fruindo, em igual proporção, desta dúplice garantia concedida pelos dois sistemas protetivos.

Assim, porque o artigo 21, da INSS/PRES 28/2008, disciplina que:

A instituição financeira, ao realizar as operações de consignação/retenção/constituição de RMC dos titulares de benefícios deverá, sem prejuízo de outras informações legais exigidas (art. 52 do Código de Defesa do Consumidor - CDC), observar a regulamentação expedida pelo Conselho Monetário Nacional e pelo Banco Central do Brasil, em especial as disposições constantes da Resolução $n^{\circ} 2.878$, de 26 de julho de 2001, e alterações posteriores, bem como dar ciência prévia ao beneficiário, no mínimo, das seguintes informações:

I - valor total com e sem juros;

II - taxa efetiva mensal e anual de juros;

III - todos os acréscimos remuneratórios, moratórios e tributários que eventualmente incidam sobre o valor do crédito contratado;

$I V$ - valor, número e periodicidade das prestações;

$V$ - soma total a pagar com o empréstimo pessoal ou cartão de crédito; $e$

VI - data do início e fim do desconto.

VII - valor da comissão paga aos terceirizados contratados pelas instituições financeiras para a operacionalização da venda do crédito, quando não for efetuado por sua própria rede.

VIII - o CNPJ da agência bancária que realizou a contratação quando realizado na própria rede, ou, o CNPJ do correspondente bancário e o CPF do agente subcontratado pelo anterior, acrescido de endereço e telefone.

Ainda neste sentido, há de se salientar a disposição contida no artigo

26, da INSS/PRES 28/2008, cujo conteúdo dispõe:

A instituição financeira deverá divulgar as regras de consignações/retenções/constituição de RMC acordadas em contrato com os beneficiários, obedecendo, nos materiais publicitários que fizer veicular, as normas do Código de Proteção e Defesa do Consumidor, em especial aquelas previstas nos arts. 37 e 52 desta Instrução Normativa.

O artigo 28, da INSS/PRES 28/2008, a sua vez, estabelece que:

A instituição financeira concedente de crédito deverá conservar os documentos que comprovam a operação pelo prazo de cinco anos, contados da data do término do contrato de empréstimo e da validade do cartão de crédito.

Com relação à contratação do mútuo bancário, os artigos $4^{\circ}, 5^{\circ}, 6^{\circ} \mathrm{e}$ $9^{\circ}$, da INSS/PRES 28/2008, dispõem que: 
Art. $4^{\circ}$ A contratação de operações de crédito consignado só poderá ocorrer, desde que:

I - a operação financeira tenha sido realizada na própria instituição financeira ou por meio do correspondente bancário a ela vinculada, na forma da Resolução Conselho Monetário Nacional $n^{\circ} 3.110$, de31 de julho de 2003, sendo a primeira responsável pelos atos praticados em seu nome; $e$

II - respeitada a quantidade máxima de seis contratos ativos para pagamento de empréstimo pessoal e um para o cartão de crédito do mesmo benefício, independentemente de eventuais saldos da margem consignável, sendo somente permitida a averbação de um novo contrato, condicionada à exclusão de um já existente.

Art. $5^{\circ}$ A instituição financeira, independentemente da modalidade de crédito adotada, somente encaminhará o arquivo para averbação de crédito após a devida assinatura do contrato por parte do beneficiário contratante, ainda que realizada por meio eletrônico.

Art. $6^{\circ}$ A inobservância do disposto no art. $5^{\circ}$ implicará total responsabilidade da instituição financeira envolvida e, em caso de reclamação registrada pelo beneficiário ou irregularidade constatada diretamente pelo INSS, a operação será considerada irregular e não autorizada, sendo motivo de exclusão da consignação. Art. $9^{\circ}$ A contratação de empréstimo e cartão de crédito somente poderá ser efetivada no Estado em que o beneficiário tem seu benefício mantido.

Por fim, com relação à conduta dos aposentados e pensionistas que desejem figurar como mutuários nas relações bancárias de empréstimo consignado em folha de pagamento, o artigo $3^{\circ}$, da INSS/PRES 28/2008, dispõe:

Os titulares de benefícios de aposentadoria e pensão por morte, pagos pela Previdência Social, poderão autorizar o desconto no respectivo benefício dos valores referentes ao pagamento de empréstimo pessoal e cartão de crédito concedidos por instituições financeiras, desde que:

I - o empréstimo seja realizado com instituição financeira que tenha celebrado convênio com o INSS/Empresa de Tecnologia e Informações da Previdência Social - Dataprev, para esse fim;

II - mediante contrato firmado e assinado com apresentação do documento de identidade elou Carteira Nacional de Habilitação - CNH, e Cadastro de Pessoa Física - CPF, junto com a autorização de consignação assinada, prevista no convênio; $e$

III - a autorização seja dada de forma expressa, por escrito ou por meio eletrônico e em caráter irrevogável e irretratável, não sendo aceita autorização dada por telefone e nem a gravação de voz reconhecida como meio de prova de ocorrência.

E dispõe o $\S 1^{\circ}$, do referido artigo, que:

Os descontos de que tratam o caput não poderão exceder o limite de $30 \%$ (trinta por cento) do valor da renda mensal do benefício, considerando que o somatório dos descontos elou retenções não exceda, no momento da contratação, após a dedução das consignações obrigatórias e voluntárias:

a) até $20 \%$ (vinte por cento) para as operações de empréstimo pessoal; $e$

b) até $10 \%$ (dez por cento) para as operações de cartão de crédito. 
Colhe-se, dessas disposições, que a atuação da autarquia previdenciária (INSS) objetiva a consecução de uma atividade intermediária de captação de recursos creditícios nos benefícios dos aposentados e pensionistas por ela gestionados e repasse aos mutuantes que, precedentemente, hajam se cadastrado junto do sistema instituído pela Empresa de Tecnologia e Informações da Previdência Social - DATAPREV, funcionando, desta forma, mais como um "organismo de ligação", supostamente, de acordo com os artigos $6^{\circ}, \S 2^{\circ}$, e 53, da INSS/PRES 28/2008, não passível de qualquer responsabilização pelo inadimplemento dos créditos.

\section{Os Princípios Norteadores da Atuação Administrativa, o Ato Administrativo e a Responsabilização do Estado}

A Administração Pública, Direta ou Indireta, qualquer que seja o âmbito de sua atuação, consoante disposição constitucional prevista no artigo 37, caput, da Magna Carta, reger-se-á pela observância dos princípios da legalidade (estrita), impessoalidade, moralidade, publicidade e eficiência.

A atuação administrativa, como se sabe, operacionaliza-se através da edição dos denominados atos administrativos, que, segundo lição de HELY LOPES MEIRELLES (2010, p. 152-153) “[...] por sua natureza, conteúdo e forma, diferenciam-se dos que emanam do Legislativo (leis) e do Judiciário (decisões judiciais), quando desempenham suas atribuições específicas de legislação e de jurisdição".

Ensina, ainda, o citado autor (2010, p. 153-154) que:

Ato administrativo é toda manifestação unilateral de vontade da Administração Pública que, agindo nessa qualidade, tenha por fim imediato adquirir, resguardar, transferir, modificar, extinguir e declarar direitos, ou impor obrigações aos administrados ou a si própria.

Esse conceito é restrito ao ato administrativo unilateral, ou seja, àquele que se forma com a vontade única da Administração, e que é o ato administrativo típico, que nos interessa neste capítulo. Os atos bilaterais constituem os contratos administrativos, estudados separadamente no capítulo seguinte. (grifos nossos)

É por meio da edição de atos administrativos que se dá vida à atuação estatal, competindo sua edição aos agentes públicos estatais, quer exerçam cargo, emprego ou função pública, e que, eventualmente, ao desviarem-se da finalidade precípua da 
Administração Pública, que é o bem estar social, adstrito aos ideais de justiça social e bem comum, quer porque hajam extrapolado os limites da estrita legalidade, ou ainda, porque sua atuação tenha se dissociado dos ideais de moralidade, honestidade e justiça, sem descurar-se dos demais princípios conducentes da Administração Pública, atraem para o Estado a responsabilização civil, cuja previsão constitucional encontra-se no artigo 37, § $6^{\circ}$, da Magna Carta ("As pessoas jurídicas de direito público e as de direito privado prestadoras de serviços públicos responderão pelos danos que seus agentes, nessa qualidade, causarem a terceiros, assegurado o direito de regresso contra o responsável nos casos de dolo ou culpa").

A responsabilização civil do Estado, hodiernamente, consoante a melhor doutrina, é objetiva, não havendo falar-se em perquirição de culpa da Administração Pública no exercício de suas atribuições. Cite-se (MEIRELLES, 2010, p. 685-686):

$O \S 6^{\circ}$ do art. 37 da CF seguiu a linha traçada nas Constituições anteriores, $e$, abandonando a privatística teoria subjetiva da culpa, orientou-se pela doutrina do Direito Público e manteve a responsabilidade civil objetiva da Administração, sob a modalidade do risco administrativo. Não chegou, porém, aos extremos do risco integral. $E^{\prime}$ o que se infere do texto constitucional e tem sido admitido reiteradamente pela jurisprudência, com apoio na melhor doutrina, como veremos a seguir.

$[\ldots]$

O exame desse dispositivo revela que o constituinte estabeleceu para todas as entidades estatais e seus desmembramentos administrativos a obrigação de indenizar o dano causado a terceiros por seus servidores, independentemente da prova de culpa no cometimento da lesão. Firmou, assim, o princípio objetivo da responsabilidade sem culpa pela atuação lesiva dos agentes públicos e seus delegados. Em edições anteriores, influenciados pela letra da norma constitucional, entendemos excluídas da aplicação desse princípio as pessoas físicas e as pessoas jurídicas que exerçam funções públicas delegadas, sob a forma de empresas estatais ou de empresas concessionárias ou permissionárias de serviços públicos. Todavia, evoluímos no sentido de que também estas respondem objetivamente pelos danos que seus empregados, nessa qualidade, causarem a terceiros, pois como dissemos precedentemente (cap. VI, item 1.2), não é justo e jurídico que a só transferência da execução de uma obra ou de um serviço originariamente público a particular descaracterize sua intrínseca natureza estatal e libere o executor privado das responsabilidades que teria o Poder Público se o executasse diretamente, criando maiores ônus de prova ao lesado.

Ressuma evidente, portanto, que a Administração Pública responde objetivamente pelos danos causados a terceiros (administrados) no exercício de suas atribuições, quer porque tenha adquirido, resguardado, transferido, modificado, extinguido e declarado direitos, ou imposto obrigações aos seus administrados e, de qualquer destes atos administrativos, haja se originado um dano à esfera jurídica patrimonial (“lato sensu”) destes. Contudo, a ocorrência efetiva do dano sofrido há de ser cabalmente comprovada pelo 
administrado, bem como que o nexo de causalidade entre o dano e o fato gerador guarde relação com a atuação administrativa, prescindindo-se, apenas, da perquirição da culpa ("lato sensu") do Estado.

\section{Da Responsabilidade pelos Descontos Indevidos ou A Maior de Créditos Bancários em Benefícios Previdenciários}

Ocorre diversas vezes de, no transcurso das operações de consignação dos créditos bancários em folha de pagamento, o aposentado ou pensionista ver-se lesado, com descontos indevidos ou a maior no montante de seu benefício previdenciário, seja porque os descontos relativos a créditos bancários não foram por ele contratados, decorrendo de fraudes; seja porque foram inobservadas as regras legais e/ou regulamentares definidas em ato próprio da autarquia previdenciária para a consecução das operações bancárias, ou ainda, porque os descontos dos créditos bancários devidamente autorizados ocorreram em percentuais superiores aos expressamente admitidos em lei, descuidando-se, assim, do caráter alimentar e de impenhorabilidade (artigo 649, IV, do Código de Processo Civil) dos benefícios previdenciários.

Em situações como essas, o aposentado ou pensionista que se vê, concomitantemente, na condição de consumidor e administrado, busca no seio do Judiciário, a reparação pelos danos que lhe foram causados, deparando-se, no entanto, com uma peculiar situação, a saber, a da necessária definição de quem seja o responsável pelos danos que suportou: a Administração Pública Autárquica, a instituição financeira mutuante, ou ambas, solidariamente?

A solução da quaestio in analisis tem se afigurado de difícil resolução pelos tribunais pátrios, encontrando-se posicionamentos completamente dissonantes, uns apontando para a responsabilidade exclusiva da instituição financeira, outros, pela responsabilidade exclusiva da autarquia - ainda que possua direito de regresso, e outros, ainda, para a responsabilização solidária de ambas.

Inexistem dúvidas quanto à responsabilidade civil das instituições financeiras pelos defeitos na prestação e execução dos serviços por ela ofertados no mercado de consumo, que, aliás, possui cunho objetivo (artigo 14, do Código de Defesa do Consumidor), haja vista constituir, mencionada responsabilização, decorrência lógica do 
disposto nos artigos $6^{\circ}$, VI, 14, 19 a 25, e 51, I, do Código de Defesa do Consumidor, e, 186,187 e 927, do Código Civil de 2002.

Entretanto, há de se buscar os fundamentos concernentes à responsabilidade civil da autarquia previdenciária, que atua na condição de órgão gestor intermediário (“organismo de ligação") nas operações bancárias de empréstimos bancários consignados, quando realiza descontos indevidos ou a maior nos benefícios previdenciários por ela gerenciados e mantidos, sob o fundamento de estar dando cumprimento à solicitação do próprio beneficiário, nos termos da Lei $\mathrm{n}^{\circ}$. 10.820/03 e do Decreto $\mathrm{n}^{\circ}$. 4.840/03.

Isto porque o aposentado ou pensionista, como se esposou alhures, vê-se no âmago de uma relação jurídica tripartite, em cujos pólos localizam-se $1^{\circ}$ ) o aposentado ou pensionista, figurando, concomitantemente, como consumidor, em relação à instituição financeira com a qual contrata o mútuo bancário, e, como administrado, diante do Instituto Nacional da Seguridade Social, que administra o pagamento de seus benefícios, exigi-lhe autorização prévia para os descontos mencionados, opera referidos descontos e presta-lhe contas periodicamente; $2^{\circ}$ ) a instituição financeira, na qualidade de mutuante e credora, à qual incumbe a realização de convênio com a autarquia federal, para facilitar as operações de repasse de crédito, e, "prima facie", a regularidade na contratação do mútuo bancário; e $3^{\circ}$ ) a autarquia previdenciária, que atua como órgão gestor intermediário, efetuando o pagamento dos benefícios previdenciários por ela geridos, operando os descontos expressamente autorizados, certificando-se e assegurando-se, nos termos do ato normativo regulamentar por ela editado, da regularidade da contratação do mútuo bancário, e, realizando os repasses creditícios à instituição financeira conveniada.

Resta saber se a Administração Pública envolve-se, enquanto intermediária, no conceito de relação de consumo disciplinado pela Lei $\mathrm{n}^{\circ}$. 8.078/90. A este respeito, ministra FABIO ULHOA COELHO (2002, p. 165):

A relação de consumo, tal como se pode concluir das definições contidas nos arts. $2^{\circ}$ e $3^{\circ}$ do CDC, configura o objeto da legislação protecionista do consumidor. Se o contrato envolve, de um lado, pessoa que se pode chamar de consumidora e, de outro, alguém que se poder ter por fornecedor, o regime de disciplina do referido ato encontra-se no Código de Defesa do Consumidor. Caso não seja possivel a identificação de ambos os conceitos (consumidor e fornecedor) nos pólos da relação jurídica, o assunto será estranho à incidência do regime consumerista. (grifos nossos) 
CLAUDIA LIMA MARQUES (2008, p. 85-86), no entanto, citando LEONARDO ROSCOE BESSA, leciona sobre o conceito de fornecedor equiparado, versando que:

$E ́$ o que denomina de fornecedor-equiparado, aquele terceiro na relação de consumo, um terceiro apenas intermediário ou ajudante da relação de consumo principal, mas que atua frente a um consumidor (aquele que tem seus dados cadastrados como maи pagador e não efetuou sequer uта compra) oи a um grupo de fornecedores (por exemplo, um grupo formado por um relação de consumo principal, como a de seguro de vida em grupo organizado pelo empregador e pago por este), como se fornecedor fosse (comunica o registro no banco de dados, comunica que é estipulante nos seguros de vida em grupo etc).

[...]

A figura do fornecedor equiparado, aquele que não é fornecedor do contrato principal de consumo, mas é intermediário, antigo terceiro, ou estipulante, hoje é o "dono" da relação conexa (e principal) de consumo, por deter uma posicãa de poder na relacão outra com o consumidor. É realmente uma interessante teoria, que será muito usada no futuro, ampliando - e com justiça - o campo de aplicação do $C D C$. (grifos nossos)

A autarquia previdenciária, dada sua posição de poder na relação de consumo entre mutuante e mutuário, pois é o órgão gestor dos benefícios previdenciários, dos descontos e repassases creditícios, bem como o ente legalmente legitimado à operacionalização dos negócios jurídicos previstos na Lei $\mathrm{n}^{\circ}$. 10.820/03, no mercado de consumo, vem figurar, na relação jurídica tripartite em comento, ao que parece e segundo os conceitos da melhor doutrina, como fornecedor equiparado, integrando referida relação jurídica.

Com efeito, não somente a instituição financeira, mas, igualmente, a autarquia previdenciária, diante da responsabilidade objetiva da Administração Pública (artigo $37, \S 6^{\circ}$, da Constituição Federal) pelos atos administrativos que causem prejuízo a terceiros, parece responder pelos descontos indevidamente realizados nos benefícios previdenciários dos aposentados ou pensionistas a ela vinculados, seja porque houve fraude na contratação do mútuo bancário, a exemplo da falsificação da assinatura do mutuário no contrato informado à autarquia - e o ente administrativo não a apurou oportuna e diligentemente, ou, porque houve desobediência às leis ou às normas regulamentares, a exemplo da elaboração de contrato de mútuo bancário fora do Estado de origem do benefício previdenciário consignado ou da contratação do mútuo em consignação a benefício previdenciário não alcançado pela legislação (renda mensal vitalícia, pensão vitalícia do seringueiro e benefícios assistenciais BPC, por exemplo) ou desconto em benefício de homônimo não mutuário, ou ainda, porque 
houve desconto acima dos percentuais definidos em lei (artigo $6^{\circ}, \S 5^{\circ}$, da Lei $\mathrm{n}^{\circ}$. 10.820/03 e $3^{\circ}$, da INSS/PRES 28/2008), em inobservância ao caráter alimentar dos benefícios previdenciários (AC 200871080070404/TRF4, 26.04.2010) e à impenhorabilidade que os cerca (artigo 649, IV, do Código de Processo Civil).

A jurisprudência pacificou o entendimento pela legitimidade da autarquia previdenciária para as ações desta natureza, a exemplo da AC 200861170000874/TRF3, de 25/08/2010 e da APELAÇÃO CIVEL - 501938/TRF 2, de 28/03/2011.

Quanto à responsabilização exclusiva da autarquia previdenciária por atos administrativos que impliquem descontos indevidos em benefícios previdenciários, a jurisprudência orienta-se pelo seu acolhimento. Cite-se:

CIVIL E PROCESSO CIVIL. RESPONSABILIDADE CIVIL. LEGITIMIDADE PASSIVA. INSS. DANOS MORAIS. EMPRÉSTIMO CONSIGNADO FEITO POR TERCEIRO. DESCONTOS EM BENEFÍCIO PREVIDENCIÁRIO. ILEGALIDADE. DANOS MORAIS. - Ao INSS é imputada a responsabilidade pelos danos em razão deste ter descontado dos proventos do Apelado quantia não autorizada. Em verdade, se a concretização do empréstimo dependia não só dos trâmites burocráticos entre o Requerente e a instituição financeira, mas também de comunicação de dados entre esta e o INSS e houve falha nesta última, cabe a responsabilização dos envolvidos, que será analisada no mérito. [...]

(TRF5, AC 200783000218796, Desembargador Federal Francisco Barros Dias Segunda Turma, 17/06/2010)

A divergência jurisprudencial encontra-se, na verdade, quanto à responsabilização solidária da autarquia previdenciária e da instituição financeira. Cite-se:

CIVIL. PREVIDENCIÁRIO. EMPRÉSTIMO BANCÁRIO. CONSIGNAÇÃO EM FOLHA. FRAUDE. RESPONSABILIDADE DA INSTITUIÇÃO BANCÁRIA. LEIS $N^{o}$ 10.820/03 E 10.953/2004. APELO NÃO PROVIDO. [...] 2. A Autarquia ostenta a condição de mero agente de retenção e repasse dos valores ao credor, nos empréstimos consignados de aposentados, não participando da relação de mútuo, consoante o art. $6^{\circ}$, da Lei $n^{o} 10.820 / 2003$, que dispõe sobre a autorização para desconto de prestações em folha de pagamento, com a redação dada pela Lei $n^{o}$ 10.953/2004, não tendo responsabilidade solidária, em relação às operações de empréstimos, conforme estabelece o parágrafo $2^{\circ}$ do mesmo dispositivo legal. 3. A existência de ilegalidade na contratação do empréstimo deve ser discutida em ação proposta contra o banco, que então será responsável pelo cancelamento e devolução das parcelas eventualmente indevidas que tenham sido cobradas a maior, bem como pelo pagamento de indenização por danos morais.

(AC 200683000067704, Desembargador Federal Francisco Barros Dias, TRF5 Segunda Turma, 06/05/2010) 


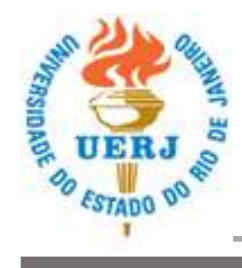

- RFID - Revista da Faculldade de Direito dla Uerj, n.32, dez. 2017

ADMINISTRATIVO. RESPONSABILIDADE CIVIL. DESCONTO NÃORECONHECIDO EM PROVENTOS DE APOSENTADORIA. DANOS MORAIS. CONFIGURAÇÃO. PLURALIDADE DE DEVEDORES. RESPONSABILIDADE SOLIDÁRIA POR ATO ILÍCITO. LITISCONSÓRCIO PASSIVO FACULTATIVO. AÇÃO PROPOSTA EM FACE DO INSS PERANTE A JUSTIÇA FEDERAL E EM FACE DA INSTITUIÇÃO FINANCEIRAS PERANTE A JUSTIÇA ESTADUAL. CONDENAÇÃO EM VALOR RAZOÁVEL NA JUSTIÇA ESTADUAL. INCINDIBILIDADE DO DANO MORAL. RECURSO IMPROVIDO.

[...] No tocante ao mérito, a questão se insere no âmbito da teoria da responsabilidade objetiva, cuja base está no art. $37, \S 6^{\circ}$, da CF, de modo ser necessário analisar três elementos: conduta, dano e nexo de causalidade. Por sua vez, a configuração de danos morais pressupõe a ocorrência de situação anormal que gere significativo abalo emocional na vítima além dos simples aborrecimentos cotidianos. [...]

Em havendo pluralidade de agentes, a responsabilidade civil por ato ilícito é solidária (art. 942, caput, do Código Civil). Dessa forma, o terceiro prejudicado, nesse caso o recorrido, pode optar por cobrar a reparação dos danos de qualquer um dos devedores ou, então, repartir entre cada um deles a parte da indenização correspondente à respectiva participação no evento danoso (art. 275 do Código Civil). [...]

( $2^{a}$ Turma Recursal dos JEFs/RJ, Processo: 200651510237599, MARCELO LUZIO MARQUES ARAUJO, Julgamento: 25.03.2008)

Para os defensores da responsabilidade solidária, o embasamento legal encontra-se no artigo 942, do Código Civil de 2002, bem como nos artigos $6^{\circ}$, VI, $7^{\circ}$, único, e 14 da Lei $n^{\circ}$. 8.078/90, contudo, ao que parece, não há a expressa previsão legal, exigida pelo artigo 265, do Código Civil, para que a solidariedade entre a instituição financeira e a autarquia previdenciária seja reconhecida, dado que "A solidariedade não se presume; resulta da lei ou da vontade das partes".

Inobstante, há, efetivamente, responsabilidade civil da autarquia previdenciária pelos descontos indevidos ou a maior nos benefícios por ela gerenciados, não sendo oponíveis às vítimas, os preceitos dos artigos $6^{\circ}, \S 2^{\circ}$, I, da Lei ${ }^{\circ}$. 10.820/03 e 53, da INSS/PRES 28/2008, porquanto referidos artigos consubstanciam excludente de responsabilidade frente ao mutuante, nada dispondo quanto ao mutuário que venha a ser lesado em sua esfera patrimonial. Ou seja, a excludente legal é expressa quanto à inexistência de solidariedade na solvência dos débitos não adimplidos pelo aposentado ou pensionista, e não, o inverso.

Este, aliás, é o posicionamento jurisprudencial. Colha-se:

RESPONSABILIDADE CIVIL. EMPRÉSTIMO CONSIGNADO EM BENEFÍCIO PREVIDENCIÁRIO (APOSENTADORIA POR INVALIDEZ). FRAUDE. DEVOLUÇÃO DOS DESCONTOS INDEVIDOS. DANOS MORAIS. [...] II- A Lei $n^{o}$ 10.820/2003 e as correspondentes Instruções Normativas editadas pelo INSS, com o intuito de estabelecer critérios e procedimentos operacionais relativos à 
consignação de descontos para pagamento de empréstimos contraídos nos benefícios da Previdência Social, bem como para limitar a responsabilidade da Autarquia, não se prestam para eximi-la quanto aos danos morais decorrentes de descontos decorrentes de fraude, tendo em vista a necessidade da mesma e de seus agentes terem um mínimo dever de cuidado relativamente às informações dos seus segurados. [...]

(TRF2, AC 200751100009601, Desembargadora Federal MARIA ALICE PAIM

LYARD - OITAVA TURMA ESPECIALIZADA, 28/02/2011)

A teoria dos motivos determinantes, igualmente, serve de fundamento à apuração da responsabilidade civil do Estado, ao determinar que “[...] os atos administrativos, quando tiverem sua prática motivada, ficam vinculados aos motivos expostos, para todos os efeitos jurídicos. Tais motivos é que determinam e justificam a realização do ato, e, por isso mesmo, deve haver perfeita correspondência entre eles e a realidade. [...] Havendo desconformidade entre os motivos determinantes e a realidade, o ato é inválido" (MEIRELLES, 2010, p. 201), ou seja, se o ente autárquico não atuou com a diligência que dele se esperava, e, procedeu a descontos indevidos ou a maior em benefícios previdenciários, com base em fatos inverídicos ou vedados em lei (falsa assinatura no contrato, contrato irregular em sua forma ou elaborado fora do Estado de origem do benefício, por exemplo), os atos administrativos que dão supedâneo a essa conduta são inválidos, por incompatibilidade com a verdade material.

\section{Conclusão}

Desta forma, presentes o dano e o nexo causal decorrente da atuação administrativa, levada a efeito nos descontos indevidos ou a maior nos benefícios previdenciários dos aposentados e pensionistas e ela vinculados, imperioso o reconhecimento do seu dever de indenizar (responsabilidade objetiva da Administração Pública), pois atua, na relação de consumo, como fornecedor equiparado, e, de tal sorte, responde pelos vícios na prestação dos serviços que intermedia, ainda que exclusivamente, em razão do âmbito dúplice de proteção ao consumidor, tutelado pela Lei $\mathrm{n}^{\circ}$. 8.078/90 e pelos princípios e normas previdenciárias, bem como aquelas regentes da Administração Pública, constituindo, tal peculiaridade, uma das novas perspectivas do Direito do Consumidor.

\section{Referências Bibliográficas}


BENJAMIN, Antônio Herman; et. al. Manual de Direito do Consumidor. 2. ed. São Paulo: Revista dos Tribunais, 2008;

CAVAlIEI FILHO, Sérgio. Programa de Responsabilidade Civil. 7. ed. São Paulo: Atlas, 2007;

COELHO, Fábio Ulhoa. Curso de Direito Comercial. vol. 3. 3. ed. São Paulo: Saraiva, 2002;

DE AGUIAR JÚNIOR, Ruy Rosado. Os Contratos Bancários e a Jurisprudência do Superior Tribunal de Justiça, p. 21. Disponível em: < http://bdjur.stj.gov.br/xmlui/bitstream/handle/2011/554/Os_Contratos_Banc\%c3\%a1rios_e_a Jurisprud\%c3\%aancia.pdf?sequence=1>, acesso em 29 de agosto de 2011;

MEIRELLES, Hely Lopes. Direito Administrativo Brasileiro. 36. ed. São Paulo: Malheiros, 2010, p.186-187; 